\title{
The outcome of vitrectomy with internal limiting membrane peeling for chronic macular hole at Biratnagar eye hospital: A tertiary eye care center in Nepal
}

\author{
Lalit Agarwal', Nisha Agrawal' ${ }^{2}$, Pratap Karki ${ }^{3}$, Abhishek Anand ${ }^{4}$ \\ ${ }^{1}$ Vitreo Retina Consultant and Head, Department of Vitreo Retina, Biratnagar Eye Hospital, ${ }^{2}$ Consultant \\ Ophthalmologist, Biratnagar Eye Hospital, Biratnagar, ${ }^{3}$ Consultant Ophthalmologist, BPKLCOS, Institute of Medicine, \\ Kathmandu, Nepal, ${ }^{4}$ Consultant Ophthalmologist, AlIMS, Patna, Bihar, India
}

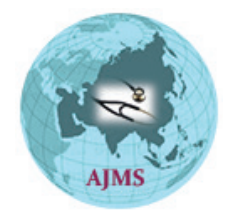

\section{A B S T R A C T}

\begin{abstract}
Background: A macular hole is a full-thickness defect of retinal tissue involving the anatomic fovea, thereby affecting central visual acuity. Pars plana vitrectomy and gas tamponade is a recognised modality of treatment for macular hole.Larger holes are more likely to remain open after repair and late reopening after an initially closed macular hole is seen in macular holes larger than $400 \mu \mathrm{m}$. Aims and Objective: To evaluate the anatomical and functional outcome of pars plana vitrectomy with internal limiting membrane peeling for chronic stage 3 macular hole. Materials and Methods: Records of 15 patients with stage 3 chronic macular holes operated from $1^{\text {st }}$ January 2013 to $30^{\text {th }}$ June 2013 and completed 1 year of follow up were retrospectively evaluated and included in the study. Preoperative best distance corrected visual acuity (BCVA), preoperative macular hole size, final BCVA and macular hole status at 1 year follow up were recorded. Macular hole closure and visual improvement was calculated. Correlation of macular hole closure and visual improvement with various macular hole parameter was estimated. Results: Eleven (73.3\%) macular holes closed at 1 year follow-up. Mean BCVA improved from $1.2 \pm 0.27$ to $0.89 \pm 0.36$ logarithm of minimum angle of resolution at 1 year $(p<0.001)$. Visual improvement was seen in only eight $(53.3 \%)$ eyes. Both macular hole closure and visual improvement showed no correlation with minimum linear diameter, base diameter and hole height. Conclusion: Chronic stage 3 macular hole can be closed successfully in majority of patients with fairly good visual improvement. Macular hole parameters of stage 3 holes may not have any correlation with the anatomical and visual outcome.
\end{abstract}

\section{Access this article online}

Website:

http://nepjol.info/index.php/AJMS DOI: 10.3126/ajms.v7i6.15419 E-ISSN: 2091-0576 P-ISSN: 2467-9100

Key words: Macular hole, Vitrectomy, ILM peeling, OCT parameters, Nepal

\section{INTRODUCTION}

A macular hole $(\mathrm{MH})$ is a full-thickness defect of retinal tissue involving the anatomic fovea, thereby affecting central visual acuity. ${ }^{1}$ It was first described in late 1800 s by Knapp and later by Noyes. ${ }^{2}$ Gass has suggested that macular holes are the result of a dehiscence of the retina at the macula, due to tangential tractional forces on the macula by the prefoveal vitreous cortex and epiretinal membranes. ${ }^{2}$
Reported prevalence of macular hole in Nepal is $0.2 \% .^{3}$ Variable data is available from different parts of the world with its prevalence ranging from $0.09 \%$ to $0.2 \% .^{3-5}$

Surgical treatment has been an accepted technique since Kelly and Wendel first reported the benefit of pars plana vitrectomy and gas tamponade in inducing closure of macular hole, flattening of the neurosensory rim and improvement in visual acuity. ${ }^{6}$ Since then there has been several modification in the surgical technique. 
Internal limiting membrane (ILM) peeling has been shown to increase the success rate in large macular hole. ${ }^{7}$ Michalewska and his colleagues reported an inverted ILM flap technique with improved anatomical and functional outcomes. ${ }^{8}$ Ocriplasmin, a truncated form of the human serine protease plasmin is now being used for nonsurgical treatment option for MH. ${ }^{9}$ The Enzymatic Vitreolysis with Ocriplasmin for Vitreomacular Traction and Macular Holes study reported a nonsurgical macular hole closure rate of $40.6 \%{ }^{9}$ The success of these surgeries is still a matter of debate for chronic stage 3 macular holes.

The postoperative closure rate for stage $3 \mathrm{MH}$ ranged from $56 \%$ to $100 \% 0^{7,10-12}$ Larger holes (mean diameter of 1205 microns) were more likely to remain open after repair and late reopening after an initially closed macular hole was seen only in macular holes larger than $400 \mu \mathrm{m} .{ }^{10,11}$ This study aims to evaluate the anatomical and functional outcome of vitrectomy in chronic stage 3 macular hole at a tertiary eye care centre in Nepal, which may help guide the decision to repair chronic macular hole.

\section{MATERIALS AND METHODS}

Retrospective interventional case series was conducted in the Vitreoretina department of Biratnagar eye hospital. Records of all patients with stage 3 chronic macular holes operated from $1^{\text {st }}$ January 2013 to $30^{\text {th }}$ June 2013 and completed 1 year of follow up were included in the study. The study adheres to tenets of Declaration of Helsinki and informed consent was obtained from all the patients prior to surgery.

Chronic macular hole was defined as duration of complain more than 1 year. ${ }^{11}$ Stage 3 macular hole was defined as minimum linear diameter (MLD) more than $400 \mu \mathrm{m}$ without posterior vitreous detachment from optic disc and macula. ${ }^{1,10} \mathrm{MH}$ size was measured with time domain optical coherence tomography (Zeiss stratus OCT). All patients had undergone 3 port 23 gauge pars plana vitrectomy (PPV) with internal limiting membrane (ILM) peeling and perflouropropane (C3F8) gas tamponade. All patients had been advised face-down positioning in the post-operative period for 10 days. Patients with corneal opacity, coexisting history of diabetes mellitus, venous occlusive disease and traumatic macular hole were excluded.

Age and gender of the patients were recorded. Preoperative best distance corrected visual acuity (BCVA), preoperative macular hole size, final BCVA and macular hole status at 1 year follow up were recorded. Macular hole was considered closed if there was no foveal neurosensory retinal defect, ${ }^{13}$ confirmed by OCT. Gain of two or more lines of Snellen's visual acuity was considered as visual improvement. Any complications in the postoperative period like retinal detachment, cystoids macular edema and late reopening of macular hole were recorded.

Statistical analysis: Data were entered in an Excel spreadsheet (Microsoft Corp.) and analyzed using SPSS software (version 16.1, SPSS, Inc.). Continuous variables were expressed as the Mean \pm Standard deviation (SD) and categorical variables were expressed as individual counts. The Snellen's visual acuity was converted into logarithm of the minimum angle of resolution (logMAR) units for analysis. Differences were considered statistically significant when the $\mathrm{p}$ value was less than 0.05 . Correlation of macular hole closure and visual improvement with various macular hole parameters (minimum linear diameter, base diameter and hole height) was estimated using spearman's rank test.

\section{RESULTS}

Fifteen patients were included in the study. Mean age of the patients was $65.3 \pm 9.0$ years (range $=50-89$ years) and male:female ratio was 7:8. Seven left eyes and 8 right eyes were operated. Mean macular hole size parameters of the patients is given in Table 1 .

Eleven $(73.3 \%)$ macular holes closed at 1 year follow-up. Mean preoperative and 1 year postoperative logMAR BCVA was $1.2 \pm 0.27$ and $0.89 \pm 0.36$ respectively (Figure 1). There was a significant improvement in BCVA at 1 year

\begin{tabular}{|c|c|c|c|c|c|}
\hline \multirow[t]{2}{*}{$\begin{array}{l}\mathrm{MH} \\
\text { parameters }\end{array}$} & \multirow[t]{2}{*}{$\begin{array}{l}\text { Mean (SD) } \\
(\mu \mathrm{m})\end{array}$} & \multicolumn{2}{|c|}{$\begin{array}{l}\text { Macular hole } \\
\text { closure }\end{array}$} & \multicolumn{2}{|c|}{$\begin{array}{c}\text { Visual } \\
\text { improvemen }\end{array}$} \\
\hline & & Rho & p value & Rho & $p$ value \\
\hline MLD & $667(134)$ & 0.139 & 0.62 & 0.12 & 0.66 \\
\hline Base diameter & $1126(350)$ & -0.371 & 0.17 & 0.24 & 0.38 \\
\hline Hole height & 698 (113) & -0.310 & 0.26 & 0.35 & 0.20 \\
\hline
\end{tabular}

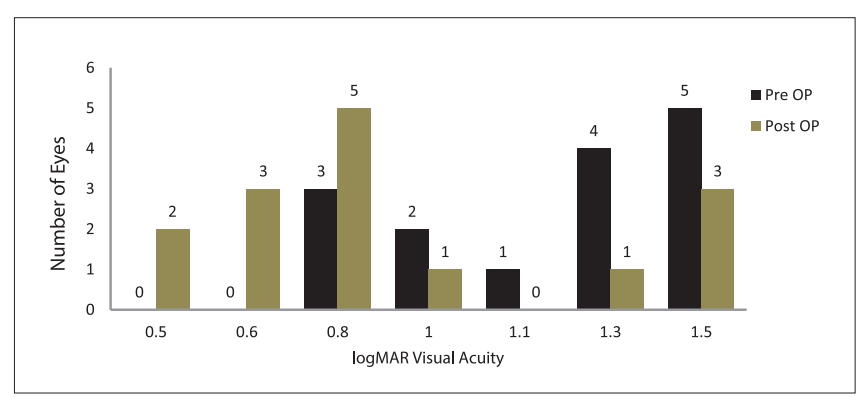

Figure 1: Pre-operative (Pre OP) and final best corrected visual acuity at 1 year (Post OP) for stage 3 macular hole 
$(\mathrm{p}<0.001)$. Visual improvement was seen in only $8(53 \%)$ eyes. None of the eyes showed a decrease in visual acuity. Both macular hole closure and visual improvement showed no correlation with MLD, base diameter and hole height (Table 1). None of the patients showed complications like retinal detachment, cystoids macular edema and late reopening of macular hole.

\section{DISCUSSION}

The management of macular hole has evolved from an untreatable condition to a microsurgical procedure with a good success rate. ${ }^{1}$ During this course, there have been several modifications in the surgical technique and adjunctive treatments. ${ }^{1}$

In various studies, macular hole closure rate ranged from $56 \%$ to $100 \% .^{7,10-12}$ In this study the hole closure rate was only $73.3 \%$ which was similar to that reported by Thapa et al. ${ }^{14}$ Similarly Shukla and colleagues reported a hole closure rate of $81 \%$ for chronic macular holes. ${ }^{11}$ As only stage 3 macular holes were included in our study, MLD ranged from 436 to $910 \mu \mathrm{m}$. Ip and associates obtained an anatomical closure rate of $56 \%$ when the $\mathrm{MH}$ was larger than $400 \mu \mathrm{m}$, whereas this percentage increased to $92 \%$ for $\mathrm{MH}$ smaller than $400 \mu \mathrm{m} .{ }^{10}$ For holes $>400 \mu \mathrm{m}$, success rate has been found to be significantly higher with face-down posturing than sitting posture after surgery (95.1\% versus $79.5 \%) .{ }^{15}$ The low rates of hole closure in our study may be attributed to poor compliance with post-operative head posturing or large hole size.

Visual improvement was seen in only $53 \%$ eyes in our study. Various authors have reported variable functional outcome for various stages of macular hole. In a study by Thapa and colleagues, this value was reported to be $45 \%$ only. ${ }^{14} 73 \%$ \& $77 \%$ of eyes had an improvement in visual acuity in studies by Shukla et al and Scott et al respectively. ${ }^{11,16} \mathrm{Kang} \mathrm{HK}$ and associates reported visual improvement in $62.5 \%$ of stage 2 and $50 \%$ stage 3 or 4 holes which was similar to that in our study. ${ }^{17}$ Several macular hole parameters have been studied for their value in predicting anatomical and visual outcomes. Base diameter, macular hole inner opening and minimum linear diameter has been found to be predictor of anatomical and functional success in macular hole surgery; base diameter holding the strongest association. ${ }^{18,19}$ However, both macular hole closure and visual improvement showed no correlation with minimum linear diameter, base diameter and hole height in our study. This may be due to the fact that only stage $3 \mathrm{MH}$ were included in our study and thus hole size larger than $400 \mu \mathrm{m}$ did not show correlation with anatomical and functional success.
Shukla et al reported that holes of greater than 3.4 years duration were associated with a greater incidence of remaining open. ${ }^{11}$ The low rates of hole closure in our study may be attributed to long duration of the disease, poor compliance with post-operative head posturing or large macular hole size. However the exact reason could not be explained. The limitation of the study is the small sample size, retrospective nature and a short follow-up.

Chronic stage 3 macular hole can be closed successfully in majority of patients with fairly good visual improvement. Macular hole parameters of stage 3 holes may not have any correlation with the anatomical and visual outcome.

\section{REFERENCES}

1. Ho AC, Guyer DR and Fine SL. Macular Hole. Surv Ophthalmol 1998; 42:393-416.

2. Gass JD. Idiopathic macular hole; its early stages and pathogenesis. Arch Ophthalmol 1988; 106: 629-639.

3. Thapa SS, Thapa R, Paudyal I, Khanal S, Aujla J, Paudyal G, et al. Prevalence and pattern of vitreo-retinal diseases in Nepal: the Bhaktapur glaucoma study. BMC Ophthalmology 2013; $13: 9$.

4. Nirmalan PK, Katz J, Robin AL, Tielsch JM, Namperumalsamy P, $\mathrm{Kim} \mathrm{R}$, et al. Prevalence of vitreoretinal disorders in a rural population of southern India: the Aravind Comprehensive Eye Study. Arch Ophthalmol 2004; 122(4):581-586.

5. Wang $\mathrm{S}, \mathrm{Xu} \mathrm{L}$ and Jonas JB. Prevalence of full-thickness macular holes in urban and rural adult Chinese: the Beijing Eye Study. Am J Ophthalmol 2006; 141(3):589-591.

6. Kelly NE and Wendel RT. Vitreous surgery for idiopathic macular holes: results of a pilot study. Arch Ophthalmol 1991; 109:654-659.

7. Tadayoni R, Gaudric A, Haouchine B and Massin P. Relationship between macular hole size and the potential benefit of internal limiting membrane peeling. Br J Ophthalmol 2006;90:1239-1241.

8. Michalewska Z, Michalewski J, Adelman RA and Nawrocki J. Inverted internal limiting membrane flap technique for large macular holes. Ophthalmology 2010;117:2018-2025.

9. Stalmans P, Benz MS, Gandorfer A, Kampik A, Girach A, Pakola S, et al. Enzymatic Vitreolysis with Ocriplasmin for Vitreomacular Traction and Macular Holes. N Engl J Med 2012; 367:606-615.

10. Ip MS, Baker BJ, Duker JS, Reichel E, Baumal CR, Gangnon R, et al. Anatomical outcomes of surgery for idiopathic macular hole as determined by optical coherence tomography. Arch Ophthalmol 2002;120(1):29-35.

11. Shukla SY, Afshar AR, Kiernan DF and Hariprasad SM. Outcomes of chronic macular hole surgical repair. Indian J Ophthalmol 2014;62:795-798.

12. Stec LA, Ross RD, Williams GA, Trese MT, Margherio RR and Cox MS. Vitrectomy for chronic macular holes. Retina 2004; 24(3):341-347.

13. Kang SW, Ahn $\mathrm{K}$ and Ham DI. Types of macular hole closure and their clinical implications. $\mathrm{Br} \mathrm{J}$ Ophthalmol 
2003;87:1015-1019.

14. Thapa R and Paudyal G. Anatomical and Visual Outcome following Macular Hole Surgery at a Tertiary Eye Care Centre in Nepal. J Nepal Med Assoc 2011; 51(183):122-127.

15. Guillaubey A, Malvitte L, Lafontaine PO, Jay N, Hubert I, Bron A, et al. Comparison of face-down and seated position after idiopathic macular hole surgery: a RCT. Am J Ophthalmol 2008;146:128-134

16. Scott IU, Moraczewski AL, Smiddy WE, Flynn HW and Feuer WJ. Long-term anatomic and visual acuity outcomes after initial anatomic success with macular hole surgery. Am J Ophthalmo 2003; 135(5):633-640.
17. Kang HK, Chang AA and Beaumont PE. The macular hole: report of an Australian surgical series and meta-analysis of the literature. Clin Experiment Ophthalmol 2000;28:298-308.

18. Wakely L, Rahman R and Stephenson J. A comparison of several methods of macular hole measurement using optical coherence tomography, and their value in predicting anatomical \& visual outcomes. Br J Ophthalmol 2012; 96:1003-1007.

19. Ruiz-Moreno JM, Staicu C, Pinero DP, Montero J, Lugo F and Amat $\mathrm{P}$. Optical coherence tomography predictive factors for macular hole surgery outcome. $\mathrm{Br} \mathrm{J}$ Ophthalmol 2008; 92:640-644.

Authors Contribution:

LA - Concept and design of study, review literature, manuscript preparation and revision; NA - Review of literature, manuscript preparation and revision;

PK - Concept and design of study, critical revision of manuscript; AA - Concept of study, review of literature. 